\title{
Educação Ambiental em Escolas Municipais de Diadema, SP: estudo de características e práxis
}

\section{Environmental Education in the Municipal Schools of Diadema, SP: a study of characteristics and praxis}

\author{
iD Elaine Angelina Colagrande ${ }^{1}$ \\ Luciana Aparecida Farias ${ }^{2}$ \\ Ana Luisa Vietti Bitencourt ${ }^{2}$ \\ Luiz Omir de Cerqueira Leite ${ }^{3}$

\begin{abstract}
'Universidade Federal de Alfenas (Unifal), Instituto de Química, Alfenas, MG, Brasil. Autora correspondente: elaine.colagrande@unifal-mg.edu.br

${ }^{2}$ Universidade Federal de São Paulo (Unifesp), Instituto de Ciências Ambientais, Químicas e Farmacêuticas, Diadema, SP' Brasil.

${ }^{3}$ Pontifícia Universidade Católica de São Paulo (PUCSP), Departamento de Ciências Sociais, São Paulo, SP, Brasil.
\end{abstract}

Resumo: A partir da percepção de que a sociedade do século XXI vem enfrentando muitos problemas socioambientais e que, considerando esse contexto, a educação ambiental (EA) torna-se uma prática essencial, esta pesquisa buscou entender a relação que a população de escolas públicas municipais da cidade de Diadema, região metropolitana de São Paulo, estabelece com o conhecimento no que tange ao meio ambiente e à EA, por meio de ações e projetos desenvolvidos nesses espaços. Esta pesquisa, de abordagem mista, utilizou análise documental e aplicação de questionário, a fim de identificar as características de EA presentes nos projetos e ações das escolas, de forma a inferir sobre seus efeitos no entendimento das questões socioambientais constantes em nossa sociedade. A partir dos resultados, foi possível refletir sobre caminhos que auxiliem futuras práticas nessas instituições.

Palavras-chave: Práticas de educação ambiental; Escola pública; Ensino fundamental; Questões socioambientais.

Abstract: Based on the perception that the 21 st century society has been facing many socio-environmental problems and that, considering this context, Environmental Education (EE) becomes an essential practice, this research sought to explain the relation that the population of municipal schools in the public network of the city of Diadema, in the metropolitan region of São Paulo, establishes with the knowledge regarding the environment and $E E$, through actions and projects developed in these spaces. This research, of a mixed approach, used documentary analysis and the application of a questionnaire in order to identify the characteristics of EE present in the school projects and actions, in order to infer the effects such characteristics on the understanding of the socio-environmental issues present in our society. From the results, it was possible to reflect on ways that will help future practices in these institutions.

Keywords: Environmental education practices; Public schools; Elementary schools; Socioenvironmental issues.

Recebido em: 25/08/2020

Aprovado em: 12/12/2020 


\section{Introdução}

A sociedade que avança o século XXI vem enfrentando diversos problemas socioambientais em uma crise civilizatória de grande proporção (LEFF, 2002), fato que torna a educação ambiental (EA) uma prática urgente, no sentido de proporcionar respeito pela vida, justiça ambiental, equidade, diversidade, sustentabilidade e beleza, conforme preconiza o prefácio da publicação intitulada Vamos cuidar do Brasil: conceitos e práticas em educação ambiental na escola (BRASIL, 2007), produzida pela Unesco (Organização das Nações Unidas para Educação, Ciência e Cultura), Ministério da Educação e Ministério do Meio Ambiente do Brasil. Contudo, para que tais valores preconizados sejam atingidos, é necessário que o ambiente escolar avance em práticas que promovam situações e experiências que favoreçam o desenvolvimento das potencialidades humanas e a compreensão da alteridade, de forma a contribuir para a formação do denominado sujeito ecológico.

De acordo com Carvalho (2012, p. 23), o conceito de "sujeito ecológico" é multifacetado, mas, em uma visão geral, seria "[...] um sujeito portador de valores éticos, atitudes e comportamentos ecologicamente orientados, que incidem sobre o plano individual e coletivo". Se pensarmos no âmbito da escola, ainda que o espaço educacional tenha, por vezes, dificuldade na efetiva implementação de uma EA que favoreça o desenvolvimento amplo da cidadania, ela precisa oferecer, a partir de seus projetos, condições mínimas para reflexão sobre a importância da formação de uma consciência ambiental, entendida aqui como consciência sobre o meio ambiente e as relações estabelecidas entre ele e a sociedade, bem como todas as situações que envolvem essas relações e seu próprio papel diante dessas questões. Nesse sentido, é importante voltarmos o nosso olhar para os espaços escolares.

O presente trabalho discute um estudo realizado com as escolas públicas municipais de ensino fundamental do município de Diadema. Tal estudo foi parte de um projeto desenvolvido pela Universidade Federal de São Paulo (Unifesp), campus Diadema, cujo objetivo foi construir um panorama do contexto socioambiental do município, culminando com a produção do livro intitulado Atlas ambiental de Diadema, em fase de elaboração. Todas as escolas municipais de Diadema participaram da pesquisa, correspondendo a 61 estabelecimentos de ensino, nos quais buscou-se avaliar as tendências teóricas e práticas de EA que estavam inseridas em seu cotidiano.

O município de Diadema está localizado na região metropolitana de São Paulo (Figura 1), em uma parte conhecida como Grande $A B C$, formada por sete municípios: Santo André, São Bernardo do Campo, São Caetano do Sul (que originaram a sigla $A B C$ ), Diadema, Mauá, Rio Grande da Serra e Ribeirão Pires. De acordo com a Fundação Seade ${ }^{1}$, a população estimada para o munícipio de Diadema, em 2020, é de 404.477 habitantes, distribuídos em uma área de $30,73 \mathrm{~km}^{2}$, dividida em 11 bairros. Ainda conforme dados do Seade, a população escolar estimada atendida pelas escolas do município, em 2019, considerando o registro de matrículas, correspondeu a 4.061 crianças nas creches municipais, 13.377 alunos na educação infantil e 12.536 alunos no ensino fundamental.

${ }^{1}$ Fundação Sistema Estadual de Análise de Dados. Disponível em: https://www.seade.gov.br/. Acesso em: 23 mar. 2021. 
A partir desse panorama apresentado, a realização da pesquisa objetivou entender as relações que as escolas municipais da rede pública de Diadema estabelecem com o conhecimento referente ao meio ambiente e à EA por meio das asserções feitas sobre o mundo e o universo escolar na forma dos projetos desenvolvidos nesses espaços formais de educação. Para tanto, foi realizada uma análise documental dos projetos políticopedagógicos fornecidos pelas escolas, bem como utilizados os dados de questionários respondidos por seus representantes gestores (direção ou coordenação pedagógica).

Figura 1 - Mapa de localização do município de Diadema
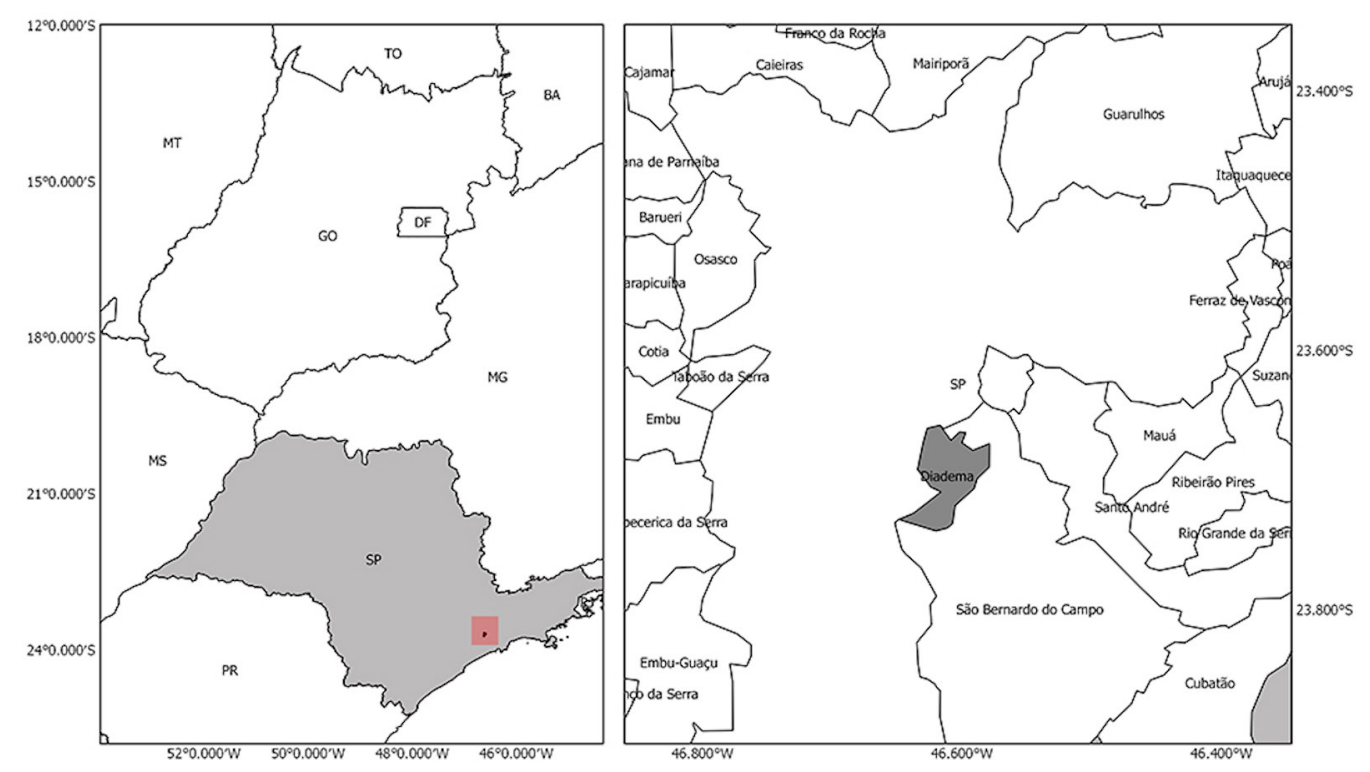

Fonte: Mapa elaborado por meio do Qgis, versão 3.10, a partir de dados cartográficos do IBGE.

Nessa análise integrada foi possível entender o contexto ambiental em que os projetos estavam inseridos e, a partir daí, identificar possíveis características de EA, considerando os referenciais adotados. Vale destacar que o entendimento sobre a EA é multifacetado e tal apontamento sobre as características apresentou como intenção fundamentar uma reflexão sobre as práticas pedagógicas desenvolvidas nessas escolas do município.

\section{Educação Ambiental e suas Faces}

As Diretrizes Curriculares para a Educação Ambiental (Resolução n. 2/2012) apontam que a EA deve ser desenvolvida de modo integrado, contínuo e interdisciplinar, em todas as etapas educativas, desde o ensino básico até o superior (BRASIL, 2012). A partir do que a legislação brasileira preconiza, é possível se pensar que existem diferentes formas para o desenvolvimento de ações de EA que possam favorecer a formação do cidadão e garantir possibilidades para seu convívio harmonioso com o ambiente natural.

Diferentes trabalhos, tanto nacionais como internacionais, vêm discutindo, ao longo das últimas décadas, a compreensão e as relações estabelecidas por diferentes setores com a EA. Sauvé (2005) identificou 15, denominadas pela autora de "correntes" 
de educação ambiental, como a naturalista, conservacionista/recursista, resolutiva, científica, dentre outras, indicando que não são excludentes e algumas compartilham características comuns. No entendimento da autora, as correntes são formas de entender e praticar a EA. Carvalho (2004) também indica que a EA tem sido categorizada com diversas denominações, como popular, política, comunitária, conservacionista e aquela para o desenvolvimento sustentável. Essas diferentes expressões confirmam a diversidade de possibilidades no entendimento dos objetivos e das práticas de EA.

Considerando a diversidade de concepções sobre a EA, Layrargues e Lima (2014) discutem três macrotendências político-pedagógicas, conforme denominação dos autores, procurando contemplar as diversas posições e práticas. A macrotendência conservacionista traz vínculos com ideias da ecologia, enfatizando os aspectos naturais e a afetividade pela natureza. De acordo com Santos e Toschi (2015), tais ideias possuem vínculo com as correntes denominadas por Sauvé (2005) de conservacionista e naturalista. A macrotendência pragmática configura-se pela preocupação com a resolução dos problemas ambientais, com base na conscientização dos cidadãos para que modifiquem suas ações individuais em prol da preservação do meio ambiente, mas sem contextualizar os aspectos sociais envolvidos nos problemas ambientais. Ela apresenta um caráter comportamentalista, pois espera a ação e mudança de cada um, não considerando o fato de que, conforme bem aponta Guimarães (2004, p. 27), "[...] a educação é relação e se dá no processo e não, simplesmente, no sucesso da mudança comportamental do indivíduo". Finalmente, a macrotendência crítica possui características opostas às linhas conservacionista e pragmática e promove o debate ambiental inserindo as dimensões políticas, sociais e culturais.

Portanto, é possível perceber que o entendimento sobre o significado da EA é diverso e multifacetado, sendo que tal diversidade de visões deve-se, em parte, às diferentes representações sociais a respeito desse tema. Algumas diretrizes são apresentadas em documentos produzidos nos encontros mundiais ocorridos ao longo do século $\mathrm{XX}$, voltados para as temáticas ambientais, bem como em diferentes documentos oficiais brasileiros, como a Lei n. 6.398/81, que instituiu a Política Nacional de Meio Ambiente, o artigo 225 da Constituição Federal de 1988, a Lei n. 9.795/99, que instituiu a Política Nacional de Educação Ambiental, e, mais recentemente, a Resolução n. 2/2012, que estabeleceu as Diretrizes Nacionais para a Educação Ambiental. A Lei n. 9.795/99 preconiza, em seu artigo 10, que a EA corresponde:

[...] aos processos por meio dos quais o indivíduo e a coletividade constroem valores sociais, conhecimentos, habilidades, atitudes e competências voltadas para a conservação do meio ambiente, bem de uso comum do povo, essencial à sadia qualidade de vida e sua sustentabilidade. (BRASIL, 1999).

Nesse sentido, no presente trabalho, optou-se por investigar as escolas participantes da pesquisa considerando as macrotendências apontadas no estudo de Layrargues e Lima (2014), pois entendeu-se que elas contemplam a diversidade de expressões e concepções da EA. O motivo de tal escolha foi definir um parâmetro mais amplo para o entendimento das práxis desenvolvidas nessas escolas. 


\section{Breve Exposição sobre a Teoria das Representações Sociais}

A teoria das representações sociais (TRS) tem sua origem na psicologia social, mas outras áreas se apropriaram de seus pressupostos, como é o caso da educação. O psicólogo social Serge Moscovici apresentou, em 1961, a teoria em seu trabalho intitulado La psychanalyse, son image et son public. Uma das formas de entendimento do autor sobre a "representação social" (RS) é que ela seria:

\footnotetext{
Um conjunto de conceitos, proposições e explicações originado na vida cotidiana no curso de comunicações interpessoais. Elas são o equivalente, em nossa sociedade, dos mitos e sistemas de crenças das sociedades tradicionais. Podem, também, ser vistas como a versão contemporânea do senso comum (MOSCOVICl, 1981, p. 181 apud SÁ, 1996, p. 31).
}

Denise Jodelet (2001, p. 22) também apresenta uma caracterização de RS como sendo "[...] uma forma de conhecimento, socialmente elaborada e partilhada, com um objetivo prático e que contribui para a construção de uma realidade comum a um conjunto social". A autora argumenta que a representação social é um saber de senso comum, que se diferencia do conhecimento científico. Esse saber é construído por meio das diferentes interações que os indivíduos experimentam ao longo de sua trajetória social e vão construindo meios próprios para explicar os fenômenos que observam (SANTOS, 2013).

A TRS vem sendo adotada há décadas para fundamentar a identificação, o entendimento e a discussão a respeito das representações de diferentes públicos (professores em formação, professores em exercício e outros campos de atuação) sobre a EA. Trabalhos em âmbitos nacional e internacional, como os de Reigota (2010), Cortes Junior e Fernandez (2016), Ramos e Monteiro (2018), Perez Mesa, Porras Contreras e Guzmán (2013), e Terrón Amigón e González Gaudiano (2009), são exemplos de estudos que utilizaram a TRS e evidenciam a importância do conhecimento das RS para a reflexão e debate sobre ações que envolvem a dimensão ambiental.

Para o presente trabalho escolheu-se a abordagem estrutural das representações sociais que corresponde à teoria do núcleo central (TNC), proposta por Jean Claude Abric, a partir de sua tese doutorado, em 1976. O autor propõe que "[...] toda realidade é representada, reapropriada pelo indivíduo ou pelo grupo, reconstruída no seu sistema cognitivo, integrada no seu sistema de valores, dependente de sua história e do contexto social e ideológico que o cerca" (ABRIC, 1998, p. 27). A TNC se articula a partir de uma hipótese geral: "[...] Toda representação se organiza em torno de um núcleo central. Esse núcleo central é o elemento fundamental da representação, pois é ele que determina ao mesmo tempo sua significação e sua organização" (ABRIC, 2001, p. 162). Para o autor, as representações sociais se organizam em dois sistemas: o central, que corresponde ao núcleo central, constituído pelos elementos mais estáveis da representação e que são resistentes a mudanças; e o sistema periférico, ou elementos periféricos que, de acordo com Abric (1998, p. 31), "[...] constituem o essencial do conteúdo da representação: seus componentes mais acessíveis, mais vivos e mais concretos". Esse sistema permite uma "[...] adaptação, uma diferenciação em função do vivido, uma integração das experiências cotidianas" (ABRIC, 1998, p. 33). 
A partir do contexto das representações sociais, optou-se pela base teórica da TCN para analisar e compreender uma das etapas do percurso metodológico desenhado para esse estudo.

\section{Metodologia}

A pesquisa relatada nesse artigo é de abordagem mista, pois utiliza elementos característicos tanto da abordagem quantitativa como da qualitativa; esse conjunto associa tais elementos em um determinado estudo (CRESWELL, 2014). Ainda de acordo com o autor, o objetivo de um estudo com abordagem mista é, a partir desse uso combinado de características, buscar maior compreensão a respeito da problemática de pesquisa. No caso do presente estudo, a parte quantitativa está vinculada à coleta de dados por questionários para entender os aspectos demográficos e sociais das instituições participantes, enquanto a parte qualitativa reside na análise e interpretação de textos presentes nos Projetos Político-Pedagógicos (PPP) das escolas, bem como no entendimento de representações sociais dos gestores. Esse conjunto possibilitou uma reflexão a respeito das práticas pedagógicas voltadas à EA que estão sendo desenvolvidas nas escolas do município.

\section{a. Os participantes da pesquisa}

A pesquisa foi desenvolvida com a população de escolas municipais da rede pública de ensino do município de Diadema. No total, 61 escolas, representadas por seus gestores (diretor e/ou coordenador pedagógico), participaram da coleta de dados ocorrida ao longo do ano letivo de 2018, após seus representantes assinarem o termo de consentimento livre e esclarecido. A pesquisa foi aprovada pelo Comitê de Ética em Pesquisa da Universidade Federal de São Paulo.

\section{b. O percurso da investigação}

O desenvolvimento da pesquisa, decorrente do projeto Atlas Ambiental de Diadema, aconteceu a partir de um convênio firmado entre a Prefeitura Municipal de Diadema e a Universidade Federal de São Paulo². Tal projeto foi composto por diferentes áreas do conhecimento, congregando pesquisadores para estudos dos segmentos componentes do Atlas: áreas de risco ambiental, arte e cultura, atmosfera/ clima, biodiversidade, direito ambiental, educação ambiental, evolução urbana e paisagem, fauna, flora, fontes poluidoras, gestão e políticas públicas, geologia, geomorfologia, identidade visual, recursos hídricos, resíduos, saneamento, saúde e meio ambiente. Com relação ao estudo do presente artigo, a equipe do projeto que tratou especificamente da temática EA visitou a população de escolas municipais, esclarecendo aos gestores sobre os objetivos do projeto e solicitando uma cópia de seus PPP e também o preenchimento do questionário produzido para a pesquisa. Todas as escolas, representadas por seus gestores, responderam ao questionário composto de 24 questões elaboradas com o propósito de conhecer os espaços escolares e,

2Convênio n. 339/2018, publicado no Diário Oficial da União em 20 de abril de 2020. 
principalmente, compreender o desenvolvimento, em seu âmbito, dos projetos relacionados ao meio ambiente.

A coleta dos dados foi composta por duas etapas, a saber:

- etapa 1: leitura e análise dos PPP fornecidos pelas escolas para identificação de atividades e ações relacionadas à EA, bem como os objetivos de tais ações;

- etapa 2: aplicação de questionário com 24 questões, divididas entre estruturadas e semiestruturadas.

Este estudo ateve-se especificamente à pergunta 9 do questionário. Sua escolha se deu por se tratar diretamente do entendimento e representação social sobre EA pelos gestores. É importante destacar que as respostas coletadas na pergunta correspondem às representações dos gestores das escolas, mas entende-se que, de alguma forma, estas exercem influência sobre as ações programadas nas instituições.

Na referida pergunta foi solicitado ao respondente que elencasse cinco palavras para o termo indutor Educação Ambiental, indicadas em ordem, da $1^{\text {a }}$ à $5^{\text {a }}$ palavra, com o objetivo de fazer com que os gestores evocassem as palavras espontaneamente, ou seja, aquelas que, pela ordem, surgiriam naturalmente em seus pensamentos a respeito da temática. Também solicitou-se que os respondentes construíssem uma frase utilizando as palavras evocadas. Essa ação teve como objetivo identificar o sentido atribuído às palavras, fato importante para a análise dos resultados, bem como sobre as concepções que os gestores possuem a respeito da temática. A partir dos dados coletados nas etapas 1 e 2, iniciou-se a análise desse corpus, que será detalhada no item resultados e discussão.

Outros dados do questionário geral, que possuem caráter sociodemográfico, foram utilizados para a construção de mapas georreferenciados, a partir da organização e geração de uma base de dados, considerando informações como: identificação das escolas; localização espacial; temas e/ou questões envolvidas na pesquisa; e condições verificadas. A localização espacial foi obtida por meio de um receptor GPS Garmim eTrex Vista, que forneceu o posicionamento pelo sistema de coordenadas planas UTM $(X, Y)$, tendo como base o sistema de referência Geodésico Brasileiro Sirgas 2000. Para cada tema pesquisado, uma planilha foi gerada contendo campos com os dados de $I D$, coordenadas $(X, Y)$ e a condição verificada: $\operatorname{sim}=1$; não=2. Para a espacialização dos pontos de coordenadas $(X, Y)$, foi utilizada a função Add XY Data do ArcMap do software ESRI ArcGIS 10, com a geração de um arquivo shape file de pontos, com respectivo sistema de referência Sirgas 2000. Os mapas foram gerados a partir dos arquivos vetoriais shape file do limite de Diadema, extraído a partir da base cartográfica do IBGE, e do shape file de pontos $(X, Y)$ criado, sendo posteriormente editado pela ferramenta de composição de mapas do ArcGIS 10.

\section{c. A análise dos dados}

Para cada etapa da metodologia, a análise ocorreu de modo diferente. Para a etapa 1, foi realizada uma análise dos PPP fornecidos pelas escolas que ocorreu da seguinte forma: a partir dos documentos disponibilizados no formato de arquivos digitais, fez-se uma busca por palavras-chave, sistematizando com o termo 
educação ambiental; pelo fato de poucos PPP apresentarem essa palavra-chave de modo explícito, realizou-se uma segunda busca, agora utilizando a palavra-chave meio ambiente, considerando que tal termo é indicado como tema transversal nos Parâmetros Curriculares Nacionais (PCN); a seguir, verificou-se o contexto em que tais palavras-chave eram citadas para que fosse possível localizar as características de EA presentes nas atividades das escolas pesquisadas. Analisaram-se também as ações programadas e descritas nos PPP que remetiam às questões ambientais indicadas para o ano letivo. A partir desse conjunto de processos - busca de palavras-chave, análise do contexto em que elas se apresentaram no documento e análise das ações planejadas e descritas -, foi realizada uma classificação de possíveis características de EA com base em Layrargues e Lima (2014), que indicam as macrotendências conservacionista, pragmática e crítica. O objetivo dessa classificação consistiu em obter indicativos da presença de características dessas macrotendências para refletir sobre as ações escolares e de formação de pessoas.

A etapa 2 abarcou a análise da pergunta 9 do questionário que foi elaborada considerando a técnica de evocação livre de palavras. Segundo Jean Claude Abric, tal técnica permite a identificação de representações sociais que nem sempre aparecem em descrições e relatos das pessoas (ABRIC, 1994 apud SÁ, 1996, p. 116). Vergès (1992 apud Sá, 1996, p. 117) propôs uma técnica para analisar essas representações que leva em conta a combinação estatística entre a frequência de evocações das palavras (número de vezes que a palavra foi citada) e a ordem de citação dessas palavras. Essa combinação é conhecida como análise prototípica. De acordo com Wachelke e Wolter (2011, p. 522) a análise prototípica "[...] parte do pressuposto que os elementos da representação social com importância em sua estrutura são mais prototípicos, isto é, mais acessíveis à consciência". Quando se faz o cruzamento das frequências das palavras evocadas com sua ordem de evocação, é possível construir um diagrama formado por quatro quadrantes, conforme apresentado na Figura 2.

Figura 2 - representação do diagrama de quatro quadrantes

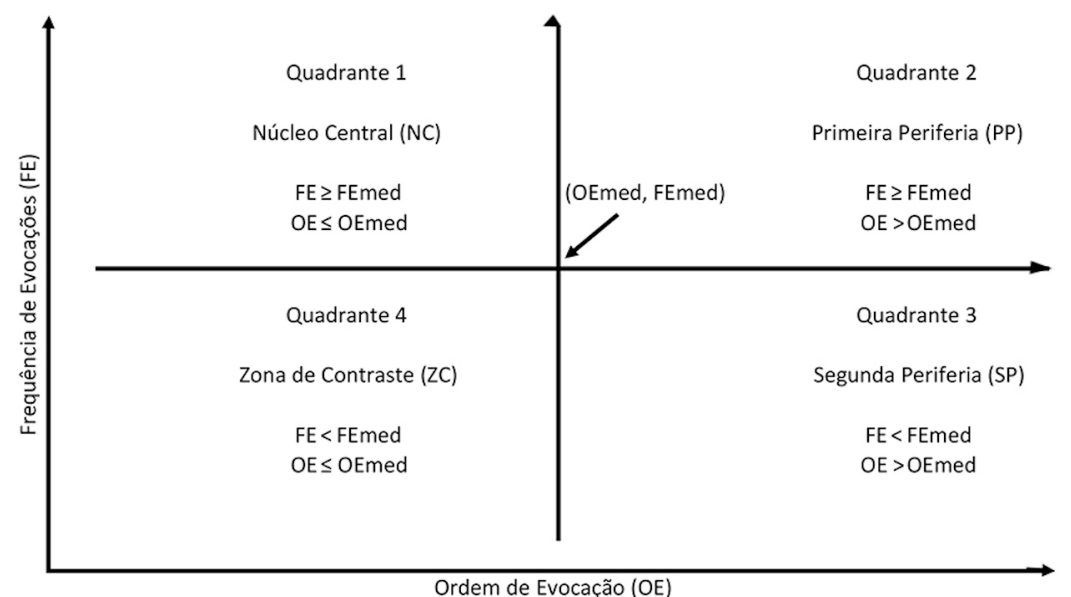

Fonte: adaptado de Oliveira et al. (2005). 
Na Figura 2 o eixo horizontal apresenta a ordem de evocação das palavras (OE) e o vertical traz a frequência com que tais palavras foram evocadas (FE). A origem dos quadrantes se dá no ponto [OEMed, FEMed], no qual OEMed corresponde à ordem de evocação média e FEMed refere-se à frequência de evocação média. O diagrama resultante é formado por quatro quadrantes que possuem características específicas: núcleo central (NC), região na qual aparecem as palavras mais importantes para os respondentes, aquelas com alta frequência e ordem de citação mais baixa; primeira periferia (PP), região que corresponde aos elementos periféricos mais evocados, mas ordem de citação mais alta do que as palavras do NC; zona de contraste (ZC), região na qual é baixa a frequência de citação das palavras, mas foram lembradas mais prontamente, em ordem mais baixa, fato que pode revelar representações com características diferenciadas; e, finalmente, a segunda periferia (SP), que corresponde à região com ordem mais alta de evocação e baixas frequências. Oliveira et al. (2005, p. 575) destacam que "[...] a técnica de evocação livre de palavras tem por objetivo apreender a percepção da realidade de um grupo social a partir de uma composição semântica preexistente".

A partir da análise prototípica sobre o tema indutor educação ambiental, foi possível construir o diagrama que mostra o panorama das representações dos gestores das escolas. Esse diagrama será detalhado na apresentação dos resultados.

\section{Resultados e Discussão}

\section{Etapa 1 - Análise dos PPP das Escolas}

Das 61 escolas participantes da pesquisa, 53 forneceram os PPP para análise e oito não o fizeram. Verificou-se que, dos 53 documentos disponíveis, apenas nove fazem referência ao termo educação ambiental de modo explícito. Isso levou a um segundo passo para verificar quais documentos citavam a temática meio ambiente. Observaram-se diferenças em relação ao primeiro, sugerindo que as escolas têm maior tendência a seguir o termo meio ambiente (Figura 3). Isso pode estar relacionado ao fato de ser um tema transversal constante nos PCN, ou por ser mais conhecido pela comunidade escolar. Entretanto, apesar de os termos estarem presentes e preconizados de algum modo no texto dos documentos escolares, isso não significa que se materializam em ações nas escolas.

Figura 3 - Presença dos termos educação ambiental e meio ambiente nos PPP
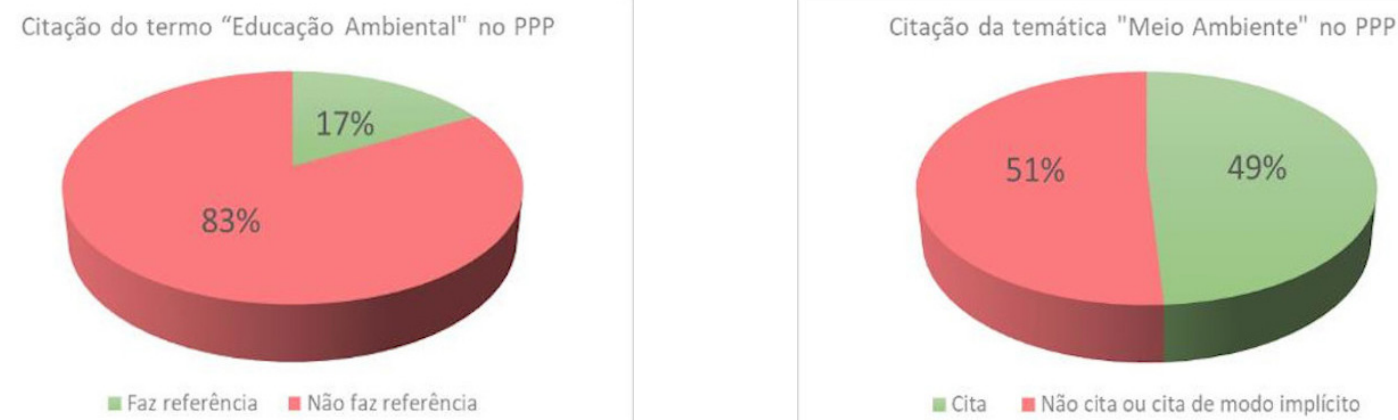

Fonte: elaborado pelos autores a partir dos dados da pesquisa. 
Após identificar a presença dos termos no PPP, a análise prosseguiu focalizando o contexto no qual tais termos eram citados nos textos. Isolaram-se as ações programadas que remetiam a discussões sobre meio ambiente e EA. A partir dessas informações foi elaborado um conjunto de categorias baseadas nas macrotendências discutidas no trabalho de Layrargues e Lima (2014) e indicadas pelas seguintes denominações: características de EA conservadora; EA pragmática; e EA crítica.

Observa-se, na Figura 4, que $60 \%$ das escolas mantêm características de práticas de EA conservadora. O restante se enquadra em características mescladas ou não trataram da temática. Apenas $4 \%$ das escolas apresentam parcialmente características da EA crítica, fato que sugere pouco entendimento sobre práticas mais amplas de educação ambiental que envolvem questões políticas, sociais e culturais, além das ambientais.

Figura 4 - Categorização das características de EA das escolas

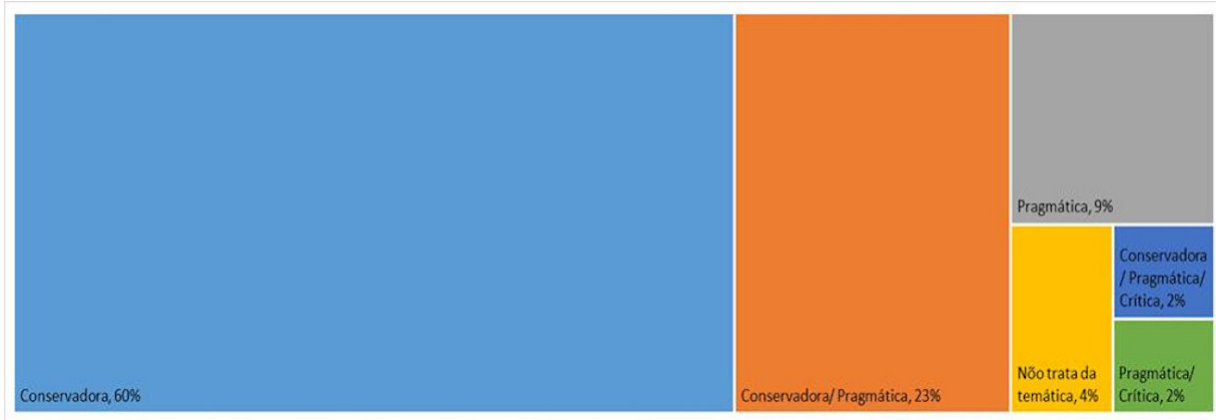

Fonte: elaborado pelos autores a partir dos dados da pesquisa.

Deve-se também considerar que as escolas pesquisadas atendem à educação infantil e ao ensino fundamental e, por isso, não é possível um entendimento maior sobre questões amplas como a EA crítica pode discutir, fato que pode ser um indicativo do alto número de escolas que apresentam características de EA conservadora e/ou pragmática. Como exemplo, citam-se os trechos das escolas codificadas pelos números 8 e 38:

Características de EA conservadora - Escola 8: Explorar o ambiente, manifestando curiosidade e interesse por plantas, animais e tudo a sua volta, preservando-o.

Características de EA pragmática - Escola 38: Meio ambiente: educar para a sustentabilidade do planeta.

Esse panorama apresentado na Figura 4 evidencia que há características mescladas (conservadora/pragmática; conservadora/pragmática/crítica; pragmática/ crítica), condição que sugere a pluralidade de expressões de EA, considerando que há diferentes atores nesses espaços (gestores, professores, funcionários e a comunidade escolar). Como ações de EA são construídas coletivamente, é fundamental conhecer e respeitar as diferentes expressões. 


\section{Etapa 2 - Análise Prototípica das Representações Sociais dos Gestores a Respeito do Termo Educação Ambiental}

Nessa etapa foram analisadas as evocações dos 60 gestores que responderam à pergunta 9 (uma escola não apresentou resposta), que tratou especificamente sobre o termo indutor educação ambiental. Como já destacado, tais

evocações indicam apenas as representações dos gestores e não da comunidade escolar. A escolha de gestores se deu por estes serem os responsáveis pelo planejamento, organização e condução de normas e ações dentro da instituição de ensino, cuidando da qualidade do que é ensinado nas escolas por meio de diversas estratégias.

$\mathrm{Na}$ construção do diagrama de quatro quadrantes, representado na Figura 5, observou-se na base de dados a presença de 108 diferentes palavras entre as 299 evocações. Com a intenção de deixar o diagrama mais direto, arbitrou-se em seis a frequência mínima para uma palavra evocada ser considerada em sua construção (evocada no mínimo por $10 \%$ dos respondentes). Foram encontradas 14 palavras nessas condições. A partir da combinação entre a frequência de evocação da palavra e sua ordem média de evocação, foi elaborado o diagrama.

Figura 5 - diagrama de representações dos gestores - tema indutor: educação ambiental

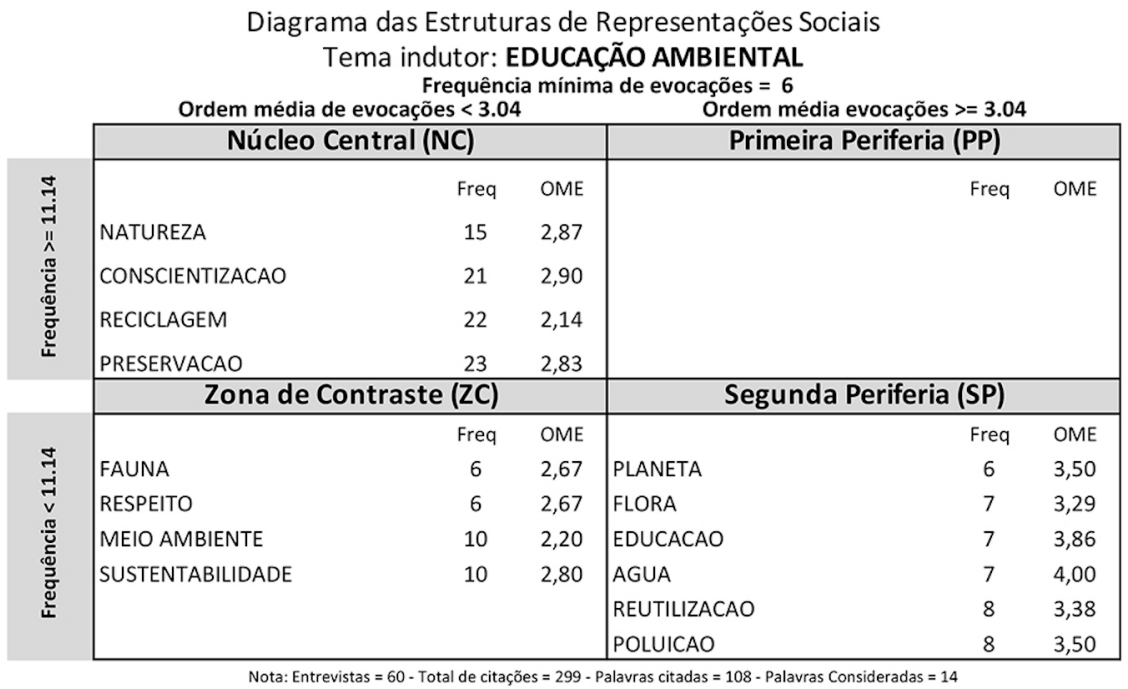

Fonte: elaborado pelos autores a partir dos dados da pesquisa.

Com o olhar voltado para o núcleo central (no qual estão presentes as representações mais resistentes), nota-se a presença de quatro palavras: natureza, conscientização, reciclagem e preservação. Quanto menor o valor de sua ordem média de citação (OME), mais prontamente a palavra foi evocada no momento de coleta dos dados da pergunta. Isto é, a palavra foi citada nas primeiras posições. A palavra reciclagem, apesar de não ser a de maior frequência de citação, foi aquela mais prontamente lembrada $(\mathrm{OME}=2,14)$. Tal situação dialoga com resultados de outras pesquisas, como as de Farias e Di Taglia (2013), Cortes Junior e Fernandes (2016) e Avila e Teixeira (2016). De modo geral, as quatro palavras que estão no núcleo central da representação mostram vínculo com as características de EA conservadora. Esse resultado coaduna com o fato de que parte expressiva das escolas (83\%) apresenta 
características de EA conservadora ou conservadora/pragmática em seus PPP (conforme Figura 4).

Outra palavra evocada foi conscientização, que geralmente é muito citada em conversas quando o assunto é direcionado a questões ambientais. Um ponto interessante a se destacar aqui é o significado do termo conscientização, que, em grande parte das vezes, é entendido como sensibilização. Tozoni-Reis (2006, p. 107) faz um relato da trajetória que o educador Paulo Freire construiu ao interpretar o significado da palavra e indica em seu trabalho que a conscientização, "[...] como princípio da educação ambiental, não é um resultado imediato da aquisição de conhecimentos sobre os processos naturais, mas a reflexão filosófica e política, carregada de escolhas históricas que resultam na busca de uma sociedade sustentável". Isso leva ao entendimento de que conscientizar é um termo mais profundo, no sentido de provocar mudanças de atitudes com relação ao meio ambiente. Foi possível perceber, a partir de algumas frases construídas pelos gestores respondentes, que o termo conscientização foi utilizado, de forma mais superficial, no sentido de sensibilização, como pode-se observar em alguns exemplos de respostas apresenta dos a seguir:

Exemplo 1: É necessário a conscientização através da educação para reutilização e redução de gêneros que possibilitem saúde ao meio ambiente.

Exemplo 2: Através da conscientização, reciclagem e respeito a natureza, poderemos chegar a preservação do meio ambiente.

$\mathrm{Na}$ primeira periferia não constam palavras classificadas. Isso significa que não ocorreram palavras com 12 ou mais evocações e que, na média da ordem, foram lembradas após a terceira posição. Nesse caso, é possível inferir que as palavras presentes no núcleo central são aquelas que foram evocadas prontamente e realmente estão mais vinculadas à temática no entendimento dos gestores. As demais palavras, constantes nos quadrantes 3 e 4 (região dos elementos periféricos), foram evocadas em menor frequência, mas também fazem parte do conjunto de representações que parecem estar relacionadas aos conceitos de educação ambiental conservadora e pragmática, como sugerem os exemplos de respostas apresentados a seguir:

Exemplo 3: A preservação, o cuidado com a nossa fauna e flora, farão o nosso futuro um exemplo de sustentabilidade.

Exemplo 4: Se faz necessário na educação ambiental uma mobilização da sociedade em relação a preservação da fauna e da flora.

Cabe destacar que a análise prototípica realizada com os dados dos gestores possui caráter exploratório, para melhor entendimento sobre as representações do grupo, e forneceu elementos para avaliar o consenso a respeito da temática educação ambiental, mas ela possui limitações, como bem destacam Wachelke, Wolter e Matos (2016). Para continuidade e aprofundamento desse estudo sobre as representações, entende-se ser necessário vincular à análise realizada outro processo de coleta de dados mais profundo, como entrevistas individuais ou em grupos, por exemplo. 
Por meio dos dados sociodemográficos coletados, foi possível a construção de mapas georreferenciados (Figura 6) que fornecem um panorama dos espaços verdes internos e do entorno das escolas, bem como as atividades que já são desenvolvidas nessas instituições.

Figura 6 - Mapas com dados de localização das escolas e situação de práticas de educação ambiental

(6a) (6b)

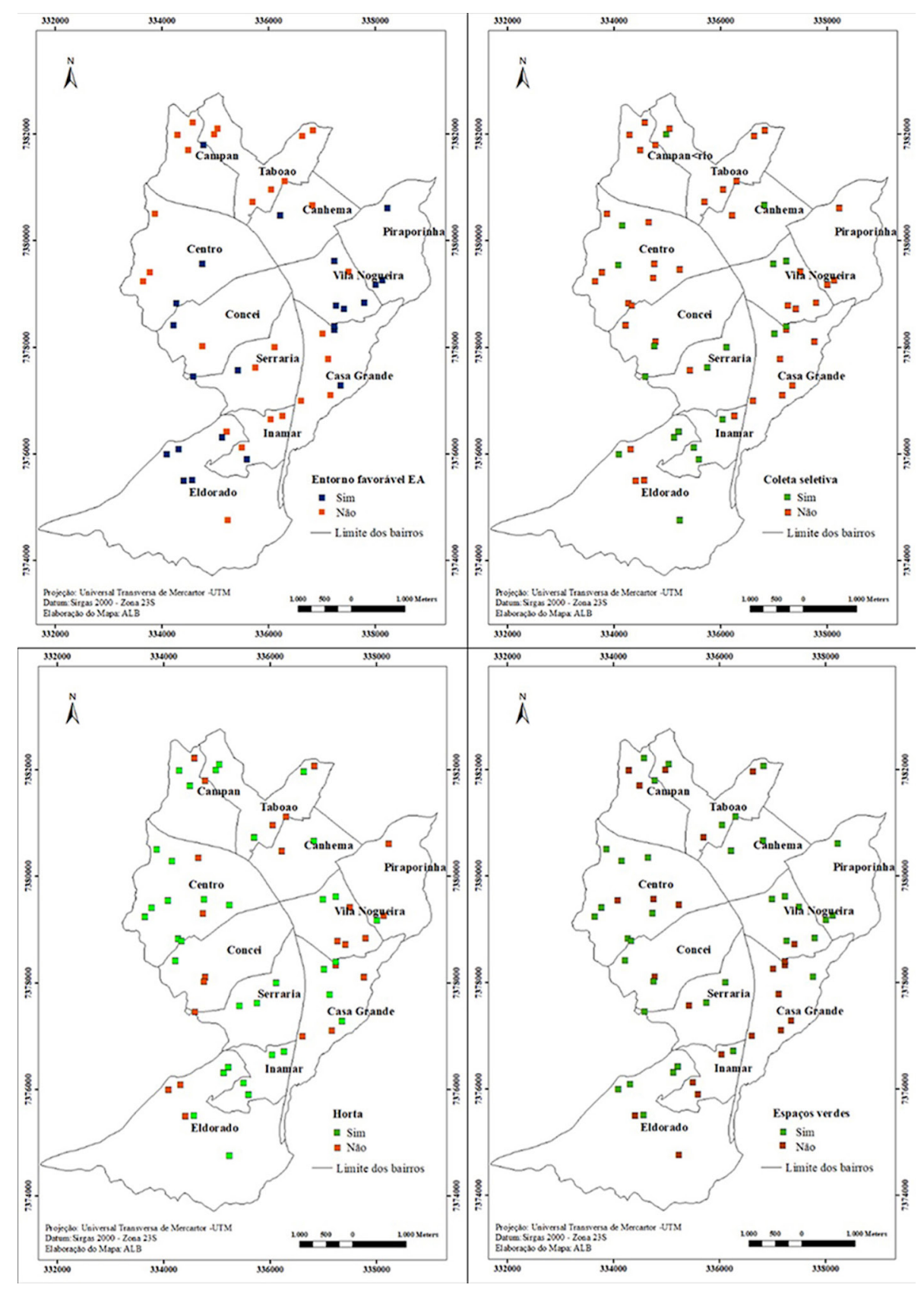

(6c)

$(6 d)$

Fonte: elaborado pelos autores a partir dos dados da pesquisa.

A Figura 6a mostra a localização das escolas que possuem entorno físico e social que favorece atividades de EA (46\%), por apresentarem espaços externos (praças, áreas verdes, espaços de convivência) que permitem, por exemplo, a realização de trilhas urbanas com o objetivo de se observar e reconhecer a realidade local, ação 
que pode desencadear processos para a construção de um pensamento mais crítico, logicamente respeitando a faixa etária e o desenvolvimento cognitivo dos estudantes. Dentre as atividades que se aproximam da EA e que são desenvolvidas pelas escolas, foram identificadas a coleta seletiva (32\%) (Figura 6b) e a horta na escola (61\%) (Figura $6 c)$. Tais atividades são as mais frequentemente abordadas nos espaços escolares, contudo, torna-se relevante um aprofundamento e acompanhamento para entender seus aspectos pedagógicos, para que não sejam ações pontuais e comportamentalistas sem uma reflexão crítica mais abrangente, considerando, novamente, a faixa etária dos alunos, dado que o entendimento das complexas relações homem-ambiente é um processo contínuo que é favorecido pelas ações escolares. Também foi possível verificar a presença de espaços verdes e de convivência no interior de grande parte das escolas (61\%) (Figura $6 \mathrm{~d}$ ), o que pode auxiliar atividades que promovam uma aproximação da comunidade escolar com questões socioambientais.

\section{Considerações Finais}

O objetivo do presente estudo foi entender as relações que as escolas municipais da rede pública de Diadema estabelecem com o conhecimento no que diz respeito ao meio ambiente e à educação ambiental na forma dos projetos desenvolvidos nesses espaços formais de educação. Tal entendimento foi possível a partir da identificação das características de EA das escolas participantes do estudo. Como produto de uma análise integrada, associando os resultados da análise dos PPP das escolas com as representações de seus gestores, é possível notar que as ações e atividades desenvolvidas nesses espaços apresentam características de EA mais conservadora e pragmática.

Os mapas georreferenciados evidenciaram que as práticas já desenvolvidas por considerável parte das escolas são aquelas mais comuns e estão distribuídas em todas as regiões do município, como a coleta seletiva de resíduos e a produção de hortas. Os mapas também mostram que o entorno externo e os espaços internos das escolas favorecem, no âmbito da EA, outras ações escolares que podem desencadear processos de conscientização, anteriormente explicitados, no sentido próprio desta palavra, que foi consideravelmente evocada nas representações dos gestores das escolas.

A identificação de características de EA das escolas, bem como das representações sociais de seus gestores, proporciona reflexões a respeito de pontos como os currículos escolares, as práticas pedagógicas e as vigentes políticas públicas que preconizam a dimensão ambiental nas instituições educacionais.

Diante das atuais questões socioambientais que envolvem a sociedade em âmbito global, é necessária uma mudança de postura no que diz respeito à relação do homem com o meio ambiente, saindo de uma visão conservadora e pragmática para uma visão mais crítica, que considera, nessa complexa relação, os aspectos sociais, políticos, econômicos e culturais. Nesse contexto, a universidade deve exercer um papel fundamental, que corresponde à abertura de espaços de formação, estudo e debate sobre tais pontos, tão importantes no cenário escolar e social.

As escolas municipais de Diadema apresentam potencialidade para o desenvolvimento de atividades de EA em todos os níveis de ensino atendidos, além 
daquelas já em andamento. Uma parceria escola-universidade para a promoção de espaços de discussão e formação permanente, em que todos os envolvidos (comunidade escolar e universidade) compartilhem experiências e construam ações de modo coletivo, fortalecerá o desenvolvimento de uma EA mais crítica e, também, poderá contribuir na formação de pessoas que ampliem valores éticos e de cidadania na busca de condições para a convivência em harmonia com o meio ambiente.

\section{Referências}

ABRIC, J. C. A abordagem estrutural das representações sociais. In: MOREIRA, A. S. P.; OLIVEIRA, D. C. (org.). Estudos interdisciplinares de representação social. Goiânia: Ed. AB, 1998. p. 27-37.

ABRIC, J. C. O estudo experimental das representações sociais. In: JODELET, D. (org.). As representações sociais. Rio de Janeiro: Ed. UERJ, 2001. p. 155-171.

AVILA, A. M.; TEIXEIRA, E. S. Representações sociais sobre educação ambiental e objetivações em práticas pedagógicas no ensino fundamental. Ciências Humanas, Frederico Westphalen, v. 17, n. 29, p. 88-104, 2016. Disponível em: https://cutt.ly/MxQ1lqH. Acesso em: 15 jul. 2020.

BRASIL. Ministério da Educação. Resolução n. 2, de 15 de junho de 2012. Estabelece as diretrizes curriculares nacionais para a educação ambiental. Brasília: MEC, 2012. Disponível em: https:// cutt.ly/Qxb0VNb. Acesso em: 19 ago. 2020.

BRASIL. Ministério do Meio Ambiente. Vamos cuidar do Brasil: conceitos e práticas em educação ambiental na escola. Brasília: MMM, 2007. Disponível em: https://cutt.ly/Xxb04lb. Acesso em: 15 jul. 2020.

BRASIL. Presidência da República. Lei n. 9.795, de 27 de abril de 1999. Dispõe sobre a educação ambiental, institui a política nacional de educação ambiental e dá outras providências. Brasília: Presidência da República, 1999. Disponível em: https://cutt.ly/uxb2Eib. Acesso em: 19 ago. 2020.

CARVALHO, I. C. M. Educação ambiental crítica: nomes e endereçamentos da educação. In: LAYRARGUES, P. P. (coord.). Identidades da educação ambiental brasileira. Brasília: MMM, 2004. p. 13-24. Disponível em: https://cutt.ly/kxb9pGX. Acesso em: 19 jul. 2020.

CARVALHO, I. C. M. Educação ambiental: a formação do sujeito ecológico. São Paulo: Cortez, 2012.

CORTES JUNIOR, L. P.; FERNANDEZ, C. A educação ambiental na formação de professores de química: estudo diagnóstico e representações sociais. Química Nova, São Paulo, v. 39, n. 6, p. 748756, 2016. DOI: http://dx.doi.org/10.5935/0100-4042.20160044.

CRESWELL, J. W. Projeto de pesquisa: métodos qualitativo, quantitativo e misto. 3. ed. Porto Alegre: Penso, 2014.

FARIAS, L. A.; DI TAGLIA, B. B. Representações sociais em torno dos termos indutores "educação ambiental" e "abordagem CTS/CTSA" entre professores do ensino médio de uma escola da rede pública de Diadema. Educação Ambiental em Ação, v. 12, n. 45, 2013. Disponível em: https://cutt. ly/yxnq3Qi. Acesso em: 19 ago. 2020.

GUIMARÃES, M. Educação ambiental crítica. In: LAYRARGUES, P. P. (coord.). Identidades da educação ambiental brasileira. Brasília: MMM, 2004. p. 25-34. Disponível em: https://cutt.ly/ kxb9pGX. Acesso em: 19 jul. 2020.

JODELET, D. Representações sociais: um domínio em expansão. In: JODELET, D. (org.). As representações sociais. Rio de Janeiro: Ed. UERJ, 2001. p. 17-44. 
LAYRARGUES, P. P.; LIMA, G. F. C. As macrotendências político-pedagógicas da educação ambiental brasileira. Ambiente \& Sociedade, v. 17, n. 1, p. 23-40, 2014. Disponível em: https://cutt. ly/Bxnwu0Q. Acesso em: 15 jul. 2020.

LEFF, E. Epistemologia ambiental. 3. ed. São Paulo: Cortez, 2002.

OLIVEIRA, D. C.; MARQUES, S. C.; GOMES, A. M. T.; TEIXEIRA, M. C. T. Análise das evocações livres: uma técnica de análise estrutural das representações sociais. In: MOREIRA, A. S. P.; CAMARGO, B. V.; JESUÍNO, J. C.; NÓBREGA, S. M. (org.). Perspectivas teórico-metodológicas em representações sociais. João Pessoa: Ed. da UFPB, 2005. p. 573-603.

PEREZ MESA, M. R.; PORRAS CONTRERAS, Y. A.; GUZMÁN, H. L. Representaciones sociales de la educación ambiental y del campus universitario: una mirada de los docentes en formación de la Universidad Pedagógica Nacional. Tecné, Episteme y Didaxis, Bogotá, n. 34, p. 47-69, 2013. Disponível em: https://cutt.ly/LxnqU3G. Acesso em: 22 out. 2020.

REIGOTA, M. Meio ambiente e representação social. 8. ed. São Paulo: Brasiliense, 2010.

RAMOS, M. T.; MONTEIRO, P. D. E. B. S. C. O. Representações sociais de professores em educação ambiental de escolas públicas municipais. Revista Brasileira de Educação Ambiental, Diadema, v. 13, n. 4, p. 281-297, 2018. DOI: https://doi.org/10.34024/revbea.2018.v13.2648.

SÁ, C. P. Núcleo central das representações sociais. Petrópolis, RJ: Vozes, 1996.

SANTOS, M. P. A teoria das representações sociais como referencial didático-metodológico de pesquisa no campo das ciências humanas e sociais aplicadas. Emancipação, Ponta Grossa, v. 13, n. 1, p. 9-21, 2013. Disponível em: https://cutt.ly/WxnsSms. Acesso em: 19 ago. 2020.

SANTOS, J.; TOSCHI, M. Vertentes da educação ambiental: da conservacionista à crítica. Fronteiras: journal of social, technological and environmental science, Anápolis, v. 4, n. 2, p. 241-250, 2015. Disponível em: https://cutt.ly/gxnfy4a. Acesso em: 19 ago. 2020.

SAUVÉ, L. Uma cartografia das correntes em educação ambiental. In: SATO, M.; CARVALHO, I. C. M. (org.). Educação ambiental. Porto Alegre: Artmed, 2005. p.17-45.

TERRÓN AMIGÓN, E. T.; GONZÁLEZ GAUDIANO, E. Representación y medio ambiente en la educación básica en México. Trayectorias, Monterrey, v. 11, n. 28, p. 58-81, 2009. Disponível em: https://cutt.ly/axngrHK. Acesso em: 22 out. 2020.

TOZONI-REIS, M. F. C. Temas ambientais como "temas geradores": contribuições para uma metodologia educativa ambiental crítica, transformadora e emancipatória. Educar em Revista, Curitiba, n. 27, p. 93-110, 2006. Disponível em: https://cutt.ly/ZxngKbK. Acesso em: 15 jul. 2020.

WACHELKE, J.; WOLTER, R. Critérios de construção e relato da análise prototípica para representações sociais. Psicologia: teoria e pesquisa, Brasília, v. 27, n. 4, p. 521-526, 2011. Disponível em: https://www.scielo.br/pdf/ptp/v27n4/17.pdf. Acesso em: 19 ago. 2020.

WACHELKE, J.; WOLTER, R.; MATOS, F. R. Efeito do tamanho da amostra na análise de evocações para representações sociais. Liberabit: revista peruana de psicologia, Lima, v. 22, n. 2, p. 153-160, 2016. Disponível em: https://cutt.ly/AxnjAk6. Acesso em: 19 ago. 2020. 